\title{
Effects of $17 \alpha$-methyltestosterone on seminal vesicle development and semen release response in the African catfish, Clarias gariepinus
}

\author{
A. T. M. Viveiros*, E. H. Eding and J. Komen ${ }^{\dagger}$ \\ Fish Culture and Fisheries Group, Wageningen Institute of Animal Sciences, Wageningen \\ University, $P O$ Box 338, 6700 AH, Wageningen, The Netherlands
}

\begin{abstract}
The effects of $17 \alpha$-methyltestosterone on seminal vesicle development in the African catfish, Clarias gariepinus, were investigated in an attempt to improve semen collection from this species. Treatment of larvae with dietary $17 \alpha-$ methyltestosterone at $50 \mathrm{mg} \mathrm{kg}^{-1}$ for days $12-33$ or days

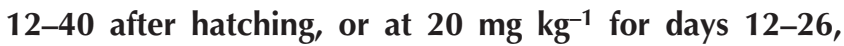
12-33, 12-40 or 12-47 after hatching inhibited the development of the seminal vesicle finger-like extensions in male catfish, but did not affect the sex ratio. The minimum effective dose and period of treatment to inhibit seminal vesicle development in all male catfish treated with $17 \alpha$ methyltestosterone was $20 \mathrm{mg} \mathrm{kg}^{-1}$ for days 12-40 after hatching. Male catfish from this treatment group developed normal testes that, in some cases, contained a few oocytes,
\end{abstract}

which tended to disappear before sexual maturation. After sexual maturation, the semen release response was evaluated in males with incomplete seminal vesicles. Fluid with viable spermatozoa was obtained after two consecutive injections of carp pituitary suspension, from 10 of 19 males that had been fed $20 \mathrm{mg} 17 \alpha$-methyltestosterone $\mathrm{kg}^{-1}$ for days 12-40 or days 12-47 after hatching, but from only 4 of 15 males that did not receive any dietary steroid. Intratesticular semen quality was not affected by $17 \alpha$ methyltestosterone treatment. The results of this study demonstrate that the absence of seminal vesicle extensions induced by treatment with $17 \alpha$-methyltestosterone facilitated the collection of semen by stripping from this species of fish.

\section{Introduction}

The African catfish, Clarias gariepinus (formerly C. lazera; Fishelson et al., 1994), is well adapted to captivity, and under conditions of $25^{\circ} \mathrm{C}$ and $12 \mathrm{~h}$ light per day, the pituitary gland stores large amounts of gonadotrophin and shows a limited continuous secretion of this hormone. The amount of gonadotrophin is sufficient for sustained gametogenesis and gonadal steroid production, but not for spontaneous semen release and male reproductive behaviour (van Oordt et al., 1987). For artificial reproduction, male catfish are killed, their testes removed and macerated, and intratesticular semen is spread over the eggs.

In a previous study on African catfish (A. T. M. Viveiros and J. Komen, unpublished), the effects of drugs that are known to increase plasma gonadotrophin concentrations were evaluated on spermiogenesis and semen release response by abdominal massage. The study tested both exogenous gonadotrophin, by injecting males with Clarias or carp pituitary suspensions (CPS), and endogenous gonadotrophin, by stimulating fish pituitary with $\mathrm{LH}$

*Present address: Dept. Zootecnia, Universidade Federal de Lavras, Lavras, MG Brazil 37200-000

${ }^{+}$Corespondence

Email: Hans.Komen@alg.venv.wau.nl releasing hormone analogue (LHRHa), LHRHa plus a dopamine antagonist or ovaprim (salmon GnRH analogue plus a dopamine antagonist). Spermiogenesis, assessed by intratesticular semen volume and sperm concentration, was improved only after two consecutive injections of cPS. Stripping of a few drops of fluid with some viable spermatozoa was possible after two consecutive injections of cPS or after combinations of cPS followed by ovaprim injections. Semen volume, spermatocrit and sperm concentration were lower in the stripped fluid than in the intratesticular semen from the same group of males. Similar inconclusive results on the semen release response and sperm production after maturational hormone treatment were described for Asian catfish, C. macrocephalus (Tan Fermin et al., 1999), Asian green catfish, Mystus nemurus (U. Schneiderat, personal communication) and Blue catfish, Ictalurus furcatus (Dunham, 1993). Collectively, these results indicate that male catfish kept in captivity cannot be stripped of semen for reasons other than the lack of a gonadotrophin surge.

Several reports have indicated that stripping of semen from catfishes is difficult because the testes are located deep within the body cavity and are covered by other organs (for example, gut and stomach). Therefore, during stripping, most of the pressure applied to the abdomen is on the other organs. In addition, the ripe milt gathers along the convex lobular edge of the testes rather than passing through the 
sperm ducts. This condition has been described for two African catfish species, C. gariepinus (Hogendoorn, 1979) and Heterobranchus longifilis (Oteme et al., 1996), for Channel catfish, Ictalurus punctatus (Legendre, 1986) and for Asian green catfish, Mystus nemurus (Christianus et al., 1998). Moreover, thick interstitial tissue surrounds the spermatogenic cell area in parts of the testis and seminal vesicle (also called glandular testis), possibly blocking sperm flow during abdominal massage (Tan Fermin et al., 1999). Furthermore, the sperm ducts are surrounded by up to 50 finger-like seminal vesicle extensions (Fishelson et al., 1994) that may prevent sperm flow when pressure is applied to the abdomen (Richter, 1976); this hypothesis is supported by preliminary results obtained in our laboratory. In the preliminary experiments, the effects of $17 \alpha$-methyltestosterone (MT), oestradiol and 11-ketoandrostenedione on gonad development and sex differentiation were investigated in the African catfish. Hormones were fed to larvae at $50 \mathrm{mg} \mathrm{kg}^{-1}$ for days 13-40 after hatching. All treatments failed to induce permanent and complete sex reversal but, unexpectedly, 13 of 68 males treated with MT and sampled at 6 months after hatching could be stripped by abdominal massage, yielding a few drops of fluid. At dissection, all males treated with MT showed incomplete development of the seminal vesicle finger-like extensions (Eding et al., 1999). Partial inhibition of male gonad development and associated ducts is in agreement with the observed feminizing action of MT and other testosterone derivatives on gonad development in the African catfish (Clariidae; van Den Hurk et al., 1989) and in Channel catfish (Ictaluridae; Davis et al., 1990).

The present study investigated the inhibitory effects of MT at different doses and periods of treatment on the development of the seminal vesicle finger-like extensions. In addition, the semen release response (stripping ability) was evaluated in males with incomplete seminal vesicles, after hormonal stimulation.

\section{Materials and Methods}

\section{Husbandry of brood stock and larvae production}

The brood stock of African catfish, $C$. gariepinus, which originated from the Central Africa Republic, has been bred for several generations in the Hatchery of Fish Culture and Fisheries Group at Wageningen University, The Netherlands. Three groups of progeny were produced, each from a different group of male and female catfish. Females were injected with $4 \mathrm{mg} \mathrm{cPS} \mathrm{kg}{ }^{-1}$ body weight and stripped $12 \mathrm{~h}$ later $\left(25^{\circ} \mathrm{C}\right)$. Eggs were fertilized with intratesticular semen obtained from a male immediately after it had been killed by an overdose of tricaine methanesulfonate (Crescent Research Chemicals, Phoenix, AZ) at a concentration of $0.8 \mathrm{~g} \mathrm{I}^{-1}$ tap water. After hatching, larvae were reared at a constant temperature $\left(27 \pm 0.5^{\circ} \mathrm{C}\right)$ and photoperiod ( $14 \mathrm{~h}$ light per day) in tanks connected to a recirculating system with a flow rate of 1-2 I per min per tank. Larvae were fed Artemia ad libitum for days 2-10 after hatching. At between day 7 and day 10 after hatching, Artemia was substituted gradually with a commercial dry feed (Nutra, Trouw France, SA). After day 11 of hatching, larvae received only dry feed.

These experiments were approved by the Ethical Committee judging Animal Experiments (DEC) of the Wageningen University, No. 98046.b.

\section{Experimental diets}

The experimental diets were prepared by the alcohol evaporation method (Guerrero, 1975). Twenty or fifty milligrams of MT (Sigma Chemical Co., St Louis, MO) was dissolved in $300 \mathrm{ml}$ of $99.6 \%(\mathrm{v} / \mathrm{v})$ ethanol and mixed carefully with $1 \mathrm{~kg}$ dry feed (MT diet at 20 or $50 \mathrm{mg} \mathrm{kg}^{-1}$, respectively). Feed was dried at room temperature in an airflow cabinet for 2 days and stored at $4{ }^{\circ} \mathrm{C}$. Control diets were mixed with ethanol only. Feed was prepared every 3 weeks and was fed to the fish according to the recommendations of the manufacturer.

During MT treatment, tanks containing fish receiving the MT diet were disconnected from the water recirculating system and were put on a flow through system, so that the hormone residue could not contaminate the water supply. One week after the MT treatments had finished, the tanks containing fish treated with MT were reconnected to the water system.

\section{Experimental design}

MT experiments. A summary of the experimental design is presented (Table 1). In total, three experiments were performed, each with a different progeny group.

The aim of Expts 1 and 2 was to confirm the inhibitory effects of MT on seminal vesicle development, as described by Eding et al. (1999). In Expt 1, two replicate groups of 500 fish were fed the MT diet at the same dose of $50 \mathrm{mg} \mathrm{kg}^{-1}$ over the same period of days 12-40 after hatching, as tested earlier, whereas two other groups of 500 fish were fed the control diet for the same period. In Expt 2, fish were fed the MT diet at 50 $\mathrm{mg} \mathrm{kg}^{-1}$, but for a shorter period of days 12-33 after hatching. Owing to low numbers of fish, only one treatment and one control group could be compared (no replicates).

On the basis of the inhibitory effects of $50 \mathrm{mg} \mathrm{MT} \mathrm{kg}^{-1}$ on the development of seminal vesicle finger-like extensions, observed in Expts 1 and 2, a larger experiment was designed. The aim of this experiment was to use a lower dose of MT to determine the shortest period necessary to inhibit the development of seminal vesicle finger-like extensions, and to minimize possible inhibitory effects on spermatogenesis caused by higher doses of MT. Therefore, in Expt 3, a progeny group was divided into three tanks. Fish in two of the tanks received the MT diet (duplicate) at $20 \mathrm{mg}$ $\mathrm{kg}^{-1}$ and fish in one tank received the control diet. Treatment started at day 12 after hatching and ceased at days 26, 33, 40 and 47 after hatching, which was achieved by taking random samples of 100 fish from each of the three 
Table 1. Experimental design used to determine the effects of $17 \alpha$-methyltestosterone on seminal vesicle development and semen release response in the African catfish, Clarias gariepinus

\begin{tabular}{lccc}
\hline Experiments & $\begin{array}{c}\text { MT dose } \\
\left(\mathrm{mg} \mathrm{kg}^{-1}\right)\end{array}$ & $\begin{array}{c}\text { Period of treatment } \\
\text { (days after hatching) }\end{array}$ & $\begin{array}{c}\text { Sampling time } \\
\text { (months after hatching) }\end{array}$ \\
\hline 1 & 50 & $12-40$ & 4 \\
2 & 50 & $12-33$ & 4 \\
3 & 20 & $12-26$ & 4 and 10 \\
& $12-33$ & 4 and 10 \\
& $12-40$ & 4,10 and $14^{\mathrm{a}}$ \\
& $12-47$ & 4,10 and $14^{\mathrm{a}}$ \\
\hline
\end{tabular}

MT: $17 \alpha$-methyltestosterone.

aOnly male catfish were sampled at 14 months after hatching.

tanks at each end point. Fish were then fed an untreated diet.

Fifty fish per treatment group from Expt 1, all fish from Expt 2 and 40 fish per treatment group from Expt 3 were sampled at 4 months after hatching, that is, after sex differentiation. Fish from Expt 3 were also sampled at 10 months after hatching to assess whether the effects of MT treatment are permanent and irreversible after sexual maturation. At 10 months, samples were collected from all fish treated with MT for days 12-26 and days 12-33 after hatching, all females treated with MT for days 12-40 and days 12-47 after hatching and from 30 fish in the control group. All males treated with MT for days $12-40$ after hatching $(n=31)$ and days $12-47$ after hatching $(n=43)$ were sexed by urogenital papilla morphology, but only five males from each group were sampled to observe seminal vesicle development. The other males of the MT-treated groups and some of the control group were used for a semen release response experiment at 14 months after hatching.

\section{Semen release response experiment}

At 14 months after hatching, 19 fish that received $20 \mathrm{mg}$ MT kg-1 and 15 MT control male fish from Expt 3 received two injections of CPS ( 8 and $10 \mathrm{mg} \mathrm{kg}^{-1}$ body weight) administered at a $48 \mathrm{~h}$ interval (A. T. M. Viveiros and J. Komen, unpublished), to test the hypothesis that the absence of seminal vesicle finger-like extensions facilitates stripping of semen, as indicated by earlier results. The pituitary glands were dissolved in $0.9 \%(\mathrm{w} / \mathrm{v}) \mathrm{NaCl}$ and were injected i.m. After the first injection, males were housed individually in $120 \mathrm{I}$ tanks $\left(25^{\circ} \mathrm{C}\right)$ to avoid aggressive interaction and to maximize care during the experimental period. Fish were sampled $12 \mathrm{~h}$ after the second injection. On the same day as the first cPS injection was administered to the other group, the remaining MTtreated $(n=22)$ and MT control $(n=15)$ males were sampled without any treatment to establish the initial condition of the gonads.

\section{Parameters used to assess the effects of MT treatments}

Fish were killed in tricaine methanesulfonate (Crescent Research Chemicals) at a concentration of $0.8 \mathrm{~g} \mathrm{l}^{-1}$ tap water. Fish with elongated and pointed urogenital papilla were classified as males, and those with a rounded papilla with a longitudinal cleft as females. Body weight, gonad and seminal vesicle mass were recorded. Gonado-somatic index (G-SI) and seminal vesicle-somatic index (SV-SI) were calculated and expressed as a percentage of gonad or seminal vesicle mass, respectively, relative to total body weight. At 4 months after hatching, seminal vesicle mass was usually $<1 \mathrm{mg}$; therefore, SV-SI was calculated only for older fish. The development of seminal vesicles was considered complete when both the basal portion of the seminal vesicle and the seminal vesicle finger-like extensions were present, and incomplete when only the basal portion was present. At 4 months after hatching, juvenile fish were sexed, according to macroscopic observation of the gonads, as: (i) 'female', when the gonads were reddish, smooth and pear-shaped; (ii) 'male', when the gonads were white-grey and long; (iii) intersex, when a red female-like part was attached to a male-like gonad; and (iv) sterile, when gonads were filiform. At 10 months after hatching, mature fish were sexed according to papilla morphology.

One gonad of each fish from Expt 3 sampled at 4 months after hatching was fixed in Bouin's fluid, dehydrated through a series of alcohol and embedded in paraffin wax. Cross-sections $(5 \mu \mathrm{m})$ were stained with Crossman for histological confirmation of the gonad sex, which was initially scored under macroscopic observation. Gonads were scored as: (i) ovary, when oocytes and ovarian cavity were distinguished; (ii) testis, when spermatogenic cysts were evident; (iii) intersex, when both oocytes and spermatogenic cysts were present; and (iv) sterile, when strands of connective tissue and degenerated seminiferous tubules were observed.

\section{Parameters used to assess semen release response and semen quality}

Male fish were killed in $0.8 \mathrm{~g}$ tricaine methanesulfonate $\mathrm{I}^{-1}$ tap water for $40 \mathrm{~min}$ and then weighed. The genital area was dried and hand pressure was applied to the fish abdomen, mid-way between the pectoral and pelvic fins, 
moving posteriorly down to the urogenital papilla (van der Waal, 1985). This process was repeated 10-15 times for each male. The stripped fluid was collected in a test tube and the volume measured. Male fish were then dissected, and the testes and seminal vesicles were removed carefully and weighed. G-SI and SV-SI were calculated. The testes were slit, intratesticular semen was squeezed out and the volume was measured. Stripped fluid and intratesticular semen were kept on crushed ice during all analyses, which were performed within $<5 \mathrm{~h}$.

All qualitative and quantitative analyses were carried out in duplicate for each intratesticular semen sample and stripped sample. Spermatocrit determination was performed in capillary tubes in a micro-haematocrit IEC MB centrifuge equipped with a capillary tube rotor at $10000 \mathrm{~g}$ for $3 \mathrm{~min}$ at room temperature. The white packed semen volume was calculated as a percentage of the total volume. For microscopic sperm counting and spectrophotometry, intratesticular semen and stripped fluid were diluted 1000 times with $0.9 \%(w / v) ~ N a C l$. A double Burker-Türk counting chamber (W. Schreck, Hofheim TS) was filled with diluted semen, and spermatozoa were counted under $\times 400$ magnification. Sperm concentration was calculated as the number of spermatozoa per $\mathrm{ml}$ of semen. Absorbance was measured using a Beckman DU-64 spectrophotometer at a wavelength of $505 \mathrm{~nm}$ in polystyrene disposable cuvettes, according to methods used by Ciereszko and Dabrowsky (1993). A solution of $0.9 \%(\mathrm{w} / \mathrm{v}) \mathrm{NaCl}$ served as a blank. Sperm production per fish was calculated on the basis of semen volume and sperm concentration using intratesticular samples. A sperm motility test was carried out only in the stripped samples to test whether there were live spermatozoa in this fluid. Fifteen microlitres of stripped fluid was mixed with $30 \mu$ lap water and observed directly at $\times 200$ magnification under a light microscope. Sperm motility was classified subjectively, according to the percentage of motile spermatozoa, as: (i) 0 , when no movement was observed; (ii) 1 , when up to $25 \%$ of spermatozoa were motile; (iii) 2 , when up to $50 \%$ of spermatozoa were motile; (iv) 3, when up to $75 \%$ of spermatozoa were motile; and (v) 4 , when $>75 \%$ of spermatozoa were motile.

After measuring the volume, both intratesticular and stripped samples from MT-treated fish stimulated with cPS were tested for fertility. One female fish was treated with 4 mg CPS $\mathrm{kg}^{-1}$ body weight and stripped of eggs $12 \mathrm{~h}$ later $\left(25^{\circ} \mathrm{C}\right)$. Approximately $0.2 \mathrm{~g}$ eggs were fertilized with $100 \mu \mathrm{l}$ of either undiluted stripped fluid or intratesticular semen diluted 200 times with $0.9 \%$ (w/v) $\mathrm{NaCl}$. Each semen sample from each male was used to fertilize two separate 0.2 g portions of eggs (duplicates). The percentage of hatched larvae was calculated after incubation at $30^{\circ} \mathrm{C}$ for $24 \mathrm{~h}$.

\section{Statistical analyses}

In each MT experiment, treatment groups were compared with the control group of the same progeny. In
Expt 1, as there was no difference between duplicates, data were pooled. In Expt 2, there was no duplicate tank, so results represent mean values of fish from the same tank. In Expt 3, mean values and frequencies were compared among treatment groups, and between treatment groups and the control. Because no difference was observed among control fish from different tanks or between MTtreated fish in duplicate tanks, data were pooled. At 10 months after hatching, only five males treated with MT for days 12-40 and days 12-47 after hatching were sampled. Therefore, G-SI and SV-SI data from these groups were not tested for significant differences.

After treatment with cPS, it was not possible to strip fluid from all male fish. Data from fish that could be stripped and from those that could not be stripped were analysed separately to detect differences in intratesticular semen quality caused by removing part of the seminal fluid. As no difference was observed between MT-treated fish in duplicate tanks, or between males treated with MT for days 12-40 and days 12-47 after hatching, or between MTcontrol groups, data were pooled.

All statistical analyses were carried out using the SAS 6.11 package (SAS Institute Inc., 1990). Frequency distribution of sex ratio, presence of ovary, testis, intersex or sterile gonads scored under histological examination, and seminal vesicle development were analysed by chi-squared test of contingency tables. Means \pm SD were calculated for G-SI, SV-SI, hatching rate and for semen analyses data, and were tested for significant differences by ANOVA using the parametric General Linear Model procedure, followed by Duncan's multiple-range test for multiple comparisons. For G-SI, SV-SI, spermatocrit values and hatching rates, the residues of each model were tested for normality using the univariate procedure. Data on spermatocrit and absorbance were regressed on sperm concentration per $\mathrm{ml}$ to obtain a linear equation. Correlation was expressed as Pearson correlation coefficient $(r)$. $P$ values were significant at $<0.05$.

\section{Results}

MT treatments at $50 \mathrm{mg} \mathrm{kg}^{-1}$ (Experiments 1 and 2)

In the MT-treated and control groups in both experiments, the sex ratio, as determined by macroscopic observation of the gonads, was not different from the expected ratio of 1:1. Fish scored as 'female' had reddish gonads with a smooth surface. Fish scored as 'male' had grey-white long gonads, but the crenated testes observed normally in male catfish were present only in the control group. All MT-treated 'males' had abnormal testes with a slightly crenated or smooth surface. Fish with intersex gonads were identified only in the group treated with MT for days $12-40$ after hatching $(n=3)$. Sterile fish were not observed macroscopically. In both Expts 1 and 2, G-SI was not affected by MT treatment (Table 2).

Control 'males' had small seminal vesicle extensions in 
Table 2. Number of African catfish, Clarias gariepinus, classified as 'female', 'male', intersex and sterile as determined by macroscopic observation, and body weight, G-SI and the number of 'males' with I-SV development, after treatment with 50 mg $17 \alpha$-methyltestosterone $\mathrm{g}^{-1}$ and sampled at 4 months after hatching

\begin{tabular}{|c|c|c|c|c|c|c|c|c|c|c|}
\hline & \multirow{2}{*}{$\begin{array}{l}\text { Period of treatment } \\
\text { (days after hatching) }\end{array}$} & \multicolumn{3}{|c|}{ 'Female' } & \multicolumn{4}{|c|}{ 'Male' } & \multirow{2}{*}{$\begin{array}{l}\text { I } \\
(n)\end{array}$} & \multirow{2}{*}{$\begin{array}{l}\mathrm{S} \\
(n)\end{array}$} \\
\hline & & $n$ & BW (g) & G-SI (\%) & $n$ & BW (g) & G-SI (\%) & $\mathrm{I}-\mathrm{SV}(n)$ & & \\
\hline \multirow[t]{2}{*}{ Expt 1} & Control & 28 & $132.3 \pm 55.4$ & $0.49 \pm 0.40^{\mathrm{a}}$ & 22 & $124.9 \pm 49.5$ & $0.28 \pm 0.08^{\mathrm{a}}$ & $0^{\mathrm{b}}$ & 0 & 0 \\
\hline & $12-40$ & 24 & $99.1 \pm 37.8$ & $0.36 \pm 0.30^{a}$ & 23 & $95.4 \pm 41.5$ & $0.13 \pm 0.09^{a}$ & $23^{a}$ & 3 & 0 \\
\hline \multirow[t]{2}{*}{ Expt 2} & Control & 7 & $70.6 \pm 26.6$ & $0.18 \pm 0.10^{\mathrm{a}}$ & 13 & $60.1 \pm 17.1$ & $0.07 \pm 0.05^{a}$ & $0^{b}$ & 0 & 0 \\
\hline & $12-33$ & 9 & $127.9 \pm 61.2$ & $0.12 \pm 0.07^{a}$ & 7 & $118.7 \pm 19.8$ & $0.05 \pm 0.03^{a}$ & $7^{a}$ & 0 & 0 \\
\hline
\end{tabular}

BW: body weight; G-SI: gonadosomatic index; I-SV: incomplete seminal vesicle development; I: intersex fish; S: sterile fish.

${ }^{a b}$ Mean values within the same column and experiment with the same superscript are not significantly different, according to Duncan's multiple-range test for G-SI and to chi-squared analysis for SV development distribution $(P<0.05)$.

Table 3. Body weight, G-SI, number of fish with I-SV and histological results of gonads scored macroscopically as 'male', 'female', intersex and sterile in African catfish, Clarias gariepinus, treated with $20 \mathrm{mg} 17 \alpha$-methyltestosterone $\mathrm{kg}^{-1}$ and sampled at 4 months after hatching (Expt 3 )

\begin{tabular}{|c|c|c|c|c|c|c|c|c|c|c|c|c|c|}
\hline \multirow{2}{*}{$\begin{array}{l}\text { Period of } \\
\text { treatment } \\
\text { (days after } \\
\text { hatching) }\end{array}$} & \multicolumn{4}{|c|}{ 'Female' } & \multicolumn{7}{|c|}{ 'Male' } & \multirow[b]{2}{*}{$\begin{array}{c}\text { I } \\
(n)\end{array}$} & \multirow[b]{2}{*}{$\begin{array}{c}\mathrm{S} \\
(n)\end{array}$} \\
\hline & $n$ & $\begin{array}{l}\text { BW } \\
\text { (g) }\end{array}$ & $\begin{array}{l}\text { GS-I } \\
(\%)\end{array}$ & $\begin{array}{l}\mathrm{O} \\
(n)\end{array}$ & $n$ & $\begin{array}{c}\text { BW } \\
\text { (g) }\end{array}$ & $\begin{array}{l}\text { G-SI } \\
(\%)\end{array}$ & $\begin{array}{c}\text { I-SV } \\
(n)\end{array}$ & $\begin{array}{c}\mathrm{T} \\
(n)\end{array}$ & $\begin{array}{l}\text { I } \\
(n)\end{array}$ & $\begin{array}{l}\text { PS } \\
(n)\end{array}$ & & \\
\hline Control & 21 & $182.3 \pm 51.8$ & $0.05 \pm 0.02^{b}$ & $21^{a}$ & 17 & $197.6 \pm 91.3$ & $0.03 \pm 0.06^{a}$ & $0^{c}$ & $14^{a}$ & $0^{c}$ & $3^{a}$ & $0^{\mathrm{a}}$ & $2^{\mathrm{a}}$ \\
\hline $12-26$ & 16 & $204.8 \pm 66.8$ & $0.07 \pm 0.02^{\mathrm{ab}}$ & $16^{\mathrm{a}}$ & 24 & $182.3 \pm 55.4$ & $0.01 \pm 0.01^{b}$ & $7^{b}$ & $24^{\mathrm{a}}$ & $0^{c}$ & $0^{b}$ & $0^{\mathrm{a}}$ & $0^{\mathrm{a}}$ \\
\hline $12-33$ & 16 & $189.3 \pm 80.7$ & $0.03 \pm 0.02^{\mathrm{c}}$ & $16^{\mathrm{a}}$ & 23 & $147.9 \pm 64.1$ & $0.01 \pm 0.01^{b}$ & $10^{\mathrm{b}}$ & $19^{a}$ & $4^{b}$ & $0^{b}$ & $0^{\mathrm{a}}$ & $0^{\mathrm{a}}$ \\
\hline $12-40$ & 14 & $149.7 \pm 117.6$ & $0.07 \pm 0.04^{\mathrm{ab}}$ & $14^{\mathrm{a}}$ & 25 & $138.5 \pm 44.6$ & $0.02 \pm 0.02^{\mathrm{ab}}$ & $25^{\mathrm{a}}$ & $16^{b}$ & $4^{b}$ & $5^{a}$ & $0^{\mathrm{a}}$ & $1^{\mathrm{a}}$ \\
\hline $12-47$ & 17 & $152.5 \pm 37.5$ & $0.08 \pm 0.03^{a}$ & $17^{a}$ & 23 & $144.7 \pm 48.9$ & $0.02 \pm 0.01^{\mathrm{ab}}$ & $23^{\mathrm{a}}$ & $7^{c}$ & $11^{\mathrm{a}}$ & $5^{a}$ & $0^{\mathrm{a}}$ & $0^{\mathrm{a}}$ \\
\hline
\end{tabular}

BW: body weight; G-SI: gonadosomatic index; I-SV: incomplete seminal vesicle development.

Histological analysis confirmed the macroscopic score of all 'female' (presence of ovary - O), sterile (S) and intersex (I) gonads.

'Male' gonads were classified histologically as testis ( $\mathrm{T}$ ), intersex (I) or testis partially sterile (PS).

abcMean values within the same column with the same superscript are not significantly different, according to Duncan's multiple-range test for G-SI and to chi-squared analysis for SV development, ovary, testis, intersex, sterile and partially sterile gonads distribution $(P<0.05)$.

each lateral side of the sperm ducts. However, MT-treated 'males' had only the basal portion of the seminal vesicle. The development of the seminal vesicle finger-like extensions was inhibited in all MT-treated 'males'.

In the control fish, an elongated and pointed urogenital male papilla was positively correlated with the presence of a 'male' gonad, as revealed at dissection. However, in MTtreated groups the urogenital papilla was of a similar form in both male and female fish.

\section{MT treatments at $20 \mathrm{mg} \mathrm{kg}^{-1}$ (Experiment 3)}

Fish sampled at 4 months after hatching. On the basis of macroscopic observation of the gonads, sex ratio was not influenced by the duration of any MT treatment.

Fish scored as 'female' had reddish gonads with a smooth surface, similar to those observed in Expts 1 and 2. Histological analyses revealed the presence of previtellogenic and vitellogenic oocytes, and an ovarian cavity in all samples, confirming the previous score of 'female' and indicating normal gonadal development and normal oogenesis, irrespective of the duration of the MT treatment. G-SI was higher $(P<0.05)$ in females treated with MT for days $12-47$ after hatching $(0.08 \%)$ and lower in females treated for days $12-33$ after hatching $(0.03 \%)$, compared with the control group $(0.05 \%$; Table 3$)$.

Fish scored as 'male' had grey-white long gonads, but the typical crenated testis was observed only in control fish, in fish treated with MT for days 12-26 after hatching and in a few fish treated with MT for days 12-33 after hatching. All 'males' treated with MT for days 12-40 and days 12-47 after hatching had abnormal testes with a slightly crenated or smooth shape. Histological analyses of these 'male' gonads revealed three categories: testis, intersex and partially sterile gonads (Table 3 ). Intersex gonads with few oocytes among testicular tissue (Fig. 1) were observed in four 'males' treated with MT for days 12-33 after hatching, in four 'males' treated with MT for days 12-40 after hatching and in 11 'males' treated with MT for days 12-47 after hatching. Partially sterile gonads with areas of vacuolized connective tissue and areas of normal seminiferous tubules were observed in five 'males' treated with MT for days 12-40 after hatching, in three 'males' treated with MT for days 12-47 after hatching and in three 'males' from the control group. However, progression of spermatogenesis was observed along the length of the 

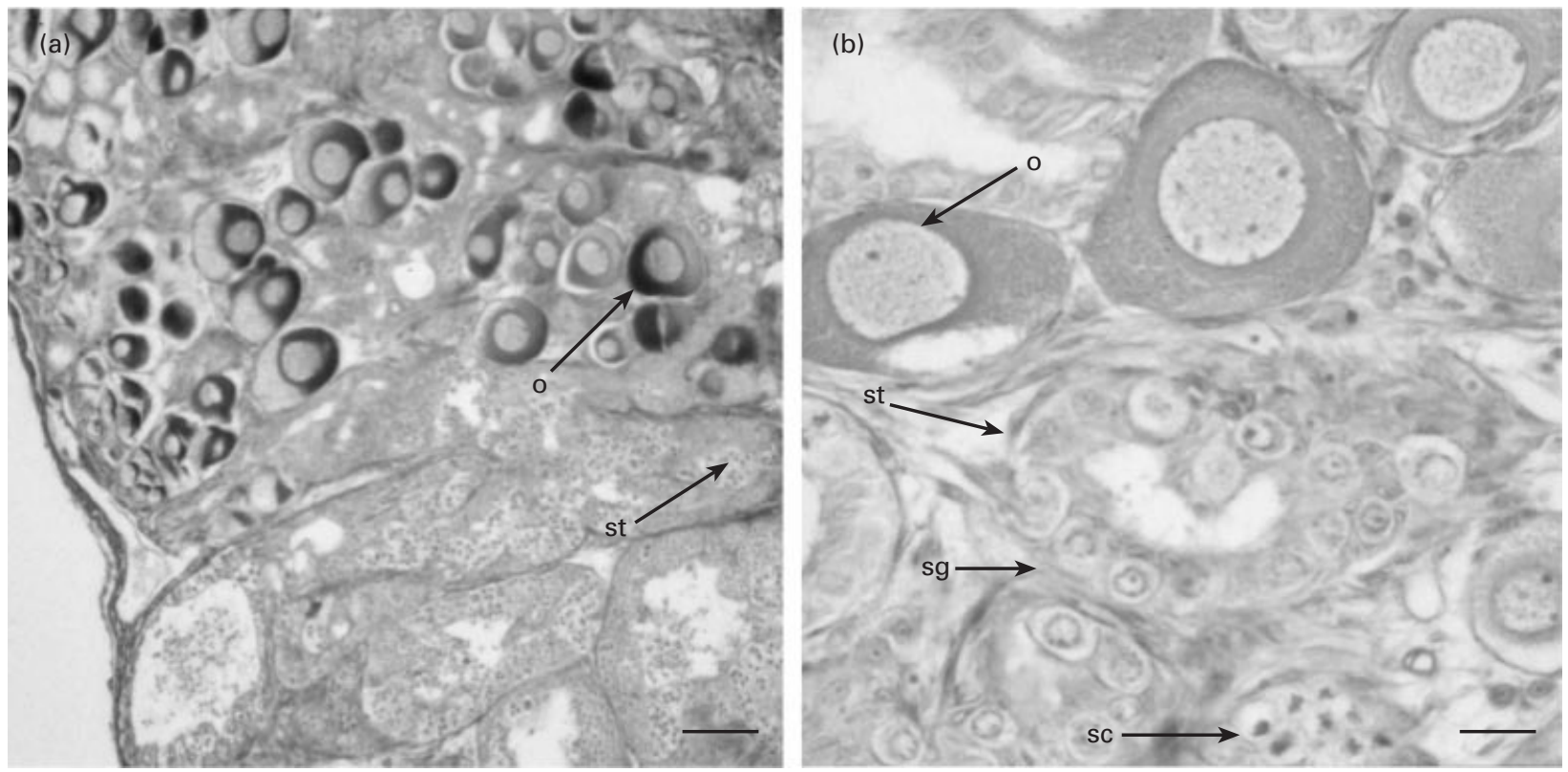

Fig. 1. Intersex gonad identified in a 'male' African catfish, Clarias gariepinus, fed $17 \alpha$-methyltestosterone for days $12-40$ after hatching and sampled at 4 months after hatching. o: oocytes; sc: spermatocyte; sg: spermatogonium; st: seminiferous tubule. Scale bars represent (a) $100 \mu \mathrm{m}$, (b) $25 \mu \mathrm{m}$.

seminiferous tubules in all testes intersex and partially sterile gonads. Each tubule was surrounded by connective tissue with blood vessels and contained irregular cysts of germ cells at different stages of development, including spermatozoa in most samples. G-SI was lower $(P<0.05)$ in 'males' treated with MT for days $12-26$ and days $12-33$ after hatching, than in control fish (Table 3).

Intersex fish were not observed macroscopically. One sterile fish was identified in the group treated with MT for days 12-40 after hatching and two in the control group, of which the gonads were not considered for G-SI calculation. Histological analyses confirmed the presence of vacuolized connective tissue and the absence of germ cells in all gonads scored macroscopically as sterile (Table 3).

In control 'males', small seminal vesicle extensions were observed in each lateral side of the sperm ducts. However, in all 'males' treated with MT for days 12-40 and days 12-47 after hatching, only the basal portion of the seminal vesicle was observed. The development of the seminal vesicle finger-like extensions was inhibited in these groups of males.

In the control fish, an elongated and pointed urogenital male papilla was positively correlated with the presence of 'male' gonads, as revealed at dissection. However, in the MT-treated groups, the urogenital papilla was of a similar form in both male and female fish.

Fish sampled at 10 months after hatching. On the basis of papilla form and including males to be sampled at 14 months after hatching, the sex ratio was not significantly different from 1:1. Ovaries were of normal morphology with post-vitellogenic oocytes in both MT-treated and control females. G-SI was significantly lower in females treated with MT for days $12-33$ and days $12-40$ after hatching, compared with control females. All males had white crenated testes and semen. The abnormal shape of the testis, observed during sampling at 4 months after hatching, was not observed in these males. Males showing one normal testis and one sterile gonad (unilateral sterile) were present in groups treated with MT for days 12-26 after hatching $(n=2)$ and for days $12-33$ after hatching $(n=3)$. In males, G-SI was not affected by any MT treatment. Intersex gonads were not identified macroscopically (Table 4).

Control males had well-developed seminal vesicles with long finger-like extensions in each lateral side of the sperm ducts. However, 4 of 36 males treated with MT for days 12-33 after hatching and all males treated with MT for days 12-40 and days 12-47 after hatching had only the basal portion of the seminal vesicle. The development of the seminal vesicle finger-like extensions was inhibited in these males. Consequently, SV-SI was significantly lower $(P<$ 0.05) in all MT-treated males compared with the control males (Table 4).

In both MT-treated and control groups, the urogenital papilla was typically pointed and elongated in males, and rounded in females. However, male fish treated with MT for days $12-40$ and days $12-47$ after hatching had a slightly smaller papilla compared with that in control males.

\section{Semen release response experiment}

Testis morphology of MT-treated males was normal and similar to that observed at 10 months after hatching. 
Table 4. Number of female and male African catfish, Clarias gariepinus, with unilateral sterile gonads or with I-SV, intersex and sterile fish as determined by macroscopic gonad observation, and G-SI and SV-SI, after treatment with 20 mg $17 \alpha$-methyltestosterone $\mathrm{kg}^{-1}$ and sampled at 10 months after hatching (Expt 3)

\begin{tabular}{|c|c|c|c|c|c|c|c|c|c|}
\hline \multirow{2}{*}{$\begin{array}{l}\text { Period of } \\
\text { treatment } \\
\text { (days after } \\
\text { hatching) }\end{array}$} & \multicolumn{2}{|c|}{ Female } & \multicolumn{5}{|c|}{ Male } & \multirow[b]{2}{*}{$\begin{array}{l}\text { I } \\
(n)\end{array}$} & \multirow[b]{2}{*}{$\begin{array}{l}\mathrm{S} \\
(n)\end{array}$} \\
\hline & $n$ & $\begin{array}{l}\text { G-SI } \\
(\%)\end{array}$ & $n$ & $\begin{array}{l}\text { G-SI } \\
(\%)\end{array}$ & $\begin{array}{l}\text { SV-SI } \\
(\%)\end{array}$ & $\begin{array}{l}\text { Unilateral } \\
\text { sterile }(n)\end{array}$ & $\begin{array}{l}\text { I-SV } \\
(n)\end{array}$ & & \\
\hline Control & 14 & $9.4 \pm 3.3^{\mathrm{a}}$ & 16 & $0.68 \pm 0.18^{a}$ & $0.29 \pm 0.06^{\mathrm{a}}$ & $0^{\mathrm{a}}$ & $0^{\mathrm{a}}$ & 0 & 0 \\
\hline $12-26$ & 38 & $8.1 \pm 2.6^{\mathrm{ab}}$ & 34 & $0.57 \pm 0.19^{a}$ & $0.18 \pm 0.07^{b}$ & $2^{\mathrm{a}}$ & $0^{\mathrm{a}}$ & 0 & 0 \\
\hline $12-33$ & 28 & $6.8 \pm 3.5^{b}$ & 36 & $0.66 \pm 0.16^{a}$ & $0.14 \pm 0.11^{b}$ & $3^{a}$ & $4^{\mathrm{a}}$ & 0 & 0 \\
\hline $12-40$ & 31 & $6.9 \pm 3.5^{b}$ & 5 & $0.87 \pm 0.32 *$ & $0.10 \pm 0.01 *$ & $0^{*}$ & $5^{*}$ & 0 & 0 \\
\hline $12-47$ & 31 & $8.3 \pm 3.5^{\mathrm{ab}}$ & 5 & $1.24 \pm 0.57^{*}$ & $0.08 \pm 0.02 *$ & $0^{*}$ & $5^{*}$ & 0 & 0 \\
\hline
\end{tabular}

G-SI: gonadosomatic index; SV-SI: seminal vesicle-somatic index; I-SV: incomplete seminal vesicle development; I: intersex fish; S: sterile fish. Unilateral sterile: males with one normal testis and one sterile gonad.

* Because only five males were tested at 10 months after hatching, statistical analysis was not carried out with this data.

abMean values within the same column with the same superscript are not significantly different, according to Duncan's multiple-range test for G-SI and SV-SI, and to chi-squared analysis for unilateral sterile gonads and SV development distribution $(P<0.05)$.

Unilateral intersex gonads were observed macroscopically in two MT-treated males. Unilateral sterile gonads were observed in one male from the control group and in six MT-treated males. However, testes mass, G-SI and intratesticular semen volume were not affected in these unilateral sterile and intersex fish in comparison with normal males.

Control males had well-developed seminal vesicles with long finger-like extensions in each lateral side of the sperm ducts. However, in all MT-treated males, the development of the seminal vesicle finger-like extensions was suppressed (Fig. 2), as indicated by the significantly lower SV-SI, compared with the control group (Table 5). The morphology of urogenital papilla was similar to that observed at 10 months after hatching.

In MT-control fish, stripping of semen was possible after cPS stimulation in 4 of 15 normal males. It was not possible to strip fluids from any of the cPS control fish. The amount of stripped fluid was small (range 0.3-0.5 ml). Mean spermatocrit values $(2.4 \%)$, sperm concentration $\left(0.5 \times 10^{9}\right.$ cells $\mathrm{ml}^{-1}$ ) and sperm motility (score: 0.8 ) were low (Table 5). In intratesticular semen samples, absorbance was significantly higher after cPS treatment in male fish that could not be stripped in comparison with male fish that could be stripped. There were no differences in the other parameters analysed between males that could be stripped and those that could not be stripped, although G-SI for non-stripped males was higher $(P<0.05)$ than for the controls, but there was no difference for stripped males. Collectively, data from stripped and non-stripped males indicate that G-SI and intratesticular semen volumes were significantly higher in cPS-treated males than in cPS-control males (Table 6). A higher intratesticular volume was accompanied by a lower sperm concentration in cPS-treated fish, so that sperm production was not affected.

In MT-treated fish, stripping of semen was possible after cPS stimulation in 10 of 19 males with incomplete seminal vesicles. It was not possible to strip semen in CPS-control fish. The amount of stripped fluid was small (range $0.2-4.0 \mathrm{ml})$. Spermatocrit values $(2.8 \%)$ and sperm concentration $\left(0.9 \times 10^{9}\right.$ cells $\left.\mathrm{ml}^{-1}\right)$ were low, but sperm motility (mean score: 1.3) was reasonable (Table 5). There was no difference in intratesticular semen results after cPS treatment between males that could be stripped and those that could not be stripped. However, SV-SI and sperm production for males that could be stripped were higher $(P<0.05)$ than those in the control males, whereas these values were not different for males that could not be stripped. Collectively, data from males that could be stripped and those that could not be stripped reveal that G-SI, SV-SI and intratesticular semen volume were significantly higher in CPS-treated males compared with cPS-control males (Table 6). However, a higher intratesticular semen volume was accompanied by a lower spermatocrit and sperm concentration $(P<0.05)$ in CPStreated fish, so that sperm production was not affected.

MT treatments did not affect the fertilizing capacity of spermatozoa after cPS stimulation. Hatching rates produced with stripped fluid $(58.9 \%)$ were not different $(P<0.05)$ from those produced with intratesticular semen from the same males $(56.5 \%)$ or from those produced with intratesticular semen from males that could not be stripped of semen $(61.8 \%)$.

A low correlation between spermatocrit and sperm concentration $(r=0.594)$ and a high correlation between absorbance at $505 \mathrm{~nm}$ and sperm concentration $(r=0.831)$ were observed when data from all 71 fish were analysed together.

\section{Discussion}

In mammals and in some amphibians, the presence of a $Y$ chromosome results in the development of the testis. In the absence of a $\mathrm{Y}$ chromosome, an ovary will develop. 

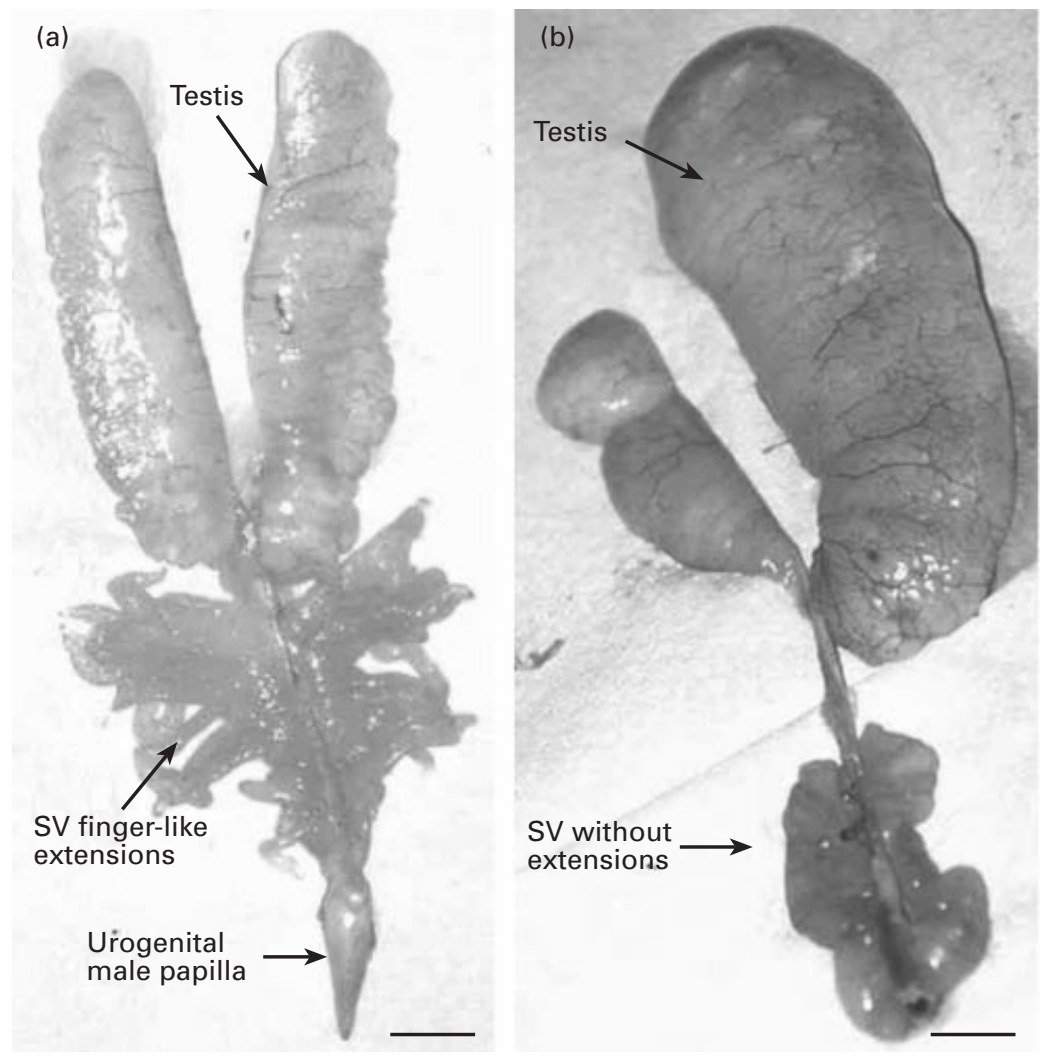

Fig. 2. Reproductive organs of a male African catfish, Clarias gariepinus, at 14 months after hatching. (a) A normal male catfish. (b) A male fed $17 \alpha$ methyltestosterone at $20 \mathrm{mg} \mathrm{kg}^{-1}$ for days 12-47 after hatching. Note the absence of seminal vesicle (SV) finger-like extensions in (b). Scale bars represent $1.5 \mathrm{~cm}$.

Thereafter, further sexual differentiation is mediated by hormones produced in the gonads (mainly sex steroids). Thus, secondary sexual characteristics are mediated by hormones and are normally confined to one or other sex, whereas gonadal sex determination is controlled by genes on a sex chromosome (Short, 1982). However, in gonochoristic fish, including catfish species, sex is predominantly determined genetically, but the process can be overruled by environmental factors (mainly temperature) and exogenous steroid hormones, resulting in a complete functional gonad sex reversal (Baroiller et al., 1999). However, gonadal sex phenotype in gonochoristic fish can be manipulated only during the pheno-critical period of gonad commitment (Davis et al., 1992; Baroiller et al., 1999). African catfish larvae maintained at $25^{\circ} \mathrm{C}$ show the first signs of histological sex differentiation at day 28 after hatching, when an ovarian cavity and germ cells with nuclei in meiotic prophase are present in half of the animals of a mixed population and the other half remain undifferentiated (presumably, the male half). Spermatogonia and Leydig cells are visible at day 42 after hatching (van Den Hurk et al., 1989), and the first signs of seminal vesicle development are observed at a later stage when the fish is approximately $70 \mathrm{~mm}$ in length (Fishelson et al., 1994). Thus, attempts to manipulate sex differentiation in African catfish should be initiated before day 28 after hatching. In the present study, catfish larvae were treated with MT, a synthetic steroid that has both masculinizing (Liu and Yao, 1995) and feminizing effects (Davis et al., 1990), and were maintained at $27^{\circ} \mathrm{C}$, a temperature known to produce a normal sex ratio in catfish (Patiño et al., 1996). Low doses and short treatments were used so that MT treatment would affect only seminal vesicle development in male fish, and would not bring about sex reversal of their gonads.

Sex ratio, assessed by gonad morphology, was not influenced by any dose of MT or by any period of treatment tested, although all treatments began before histological sex differentiation. However, all 'males' treated with MT at 20 $\mathrm{mg} \mathrm{kg}^{-1}$ for days $12-40$ and days $12-47$ after hatching, and all 'males' treated with MT at $50 \mathrm{mg} \mathrm{kg}^{-1}$, showed a change in gonad shape from the typical male-like crenated shape, to a female-like smooth shape. However, the histological results for MT-treated groups in Expt 3 showed that some of the gonads scored as 'male' morphologically were intersex. During the longest period of treatment (days 12-47 after hatching), 11 intersex fish were identified among 23 
Table 5. Quality of stripped fluid in 14-month-old African catfish, Clarias gariepinus, treated with two CPS injections ( 8 and $10 \mathrm{mg} \mathrm{kg}^{-1}$ ) administered at a $48 \mathrm{~h}$ interval and sampled $12 \mathrm{~h}$ after the second injection (stripping experiment)

\begin{tabular}{|c|c|c|c|c|}
\hline & \multicolumn{2}{|c|}{ MT-treated* } & \multicolumn{2}{|c|}{ MT-control $^{+}$} \\
\hline & cPS-treated & cPS-control & cPS-treated & cPS-control \\
\hline Treated fish $(n)$ & 19 & 22 & 15 & 15 \\
\hline Strippable fish $(n)$ & 10 & 0 & 4 & 0 \\
\hline Stripped volume (ml) & $0.7 \pm 1.2$ & - & $0.5 \pm 0.1$ & - \\
\hline Spermatocrit (\%) & $2.8 \pm 2.9$ & - & $2.4 \pm 2.8$ & - \\
\hline Cells ml-1 $\left(\times 10^{9}\right)$ & $0.9 \pm 0.8$ & - & $0.5 \pm 0.3$ & - \\
\hline Absorbance at $505 \mathrm{~nm}$ & $0.026 \pm 0.019$ & - & $0.010 \pm 0.004$ & - \\
\hline Sperm motility ${ }^{\ddagger}$ & $1.3 \pm 1.1$ & - & $0.8 \pm 0.5$ & - \\
\hline
\end{tabular}

cPS: carp pituitary suspensions; MT: $17 \alpha$-methyltestosterone.

*Males with incomplete seminal vesicles as a result of $17 \alpha$-methyltestosterone treatment during larval stages.

${ }^{+}$Males with normal seminal vesicles that were fed the control diet during larval stages.

¥Sperm motility scored as: 0 (no motile spermatozoa), 1 (1-25\%), 2 (25-50\%), 3 (50-75\%) and 4 (> 75\% motile spermatozoa).

'males'. As MT treatment has a feminizing effect in African catfish (van Den Hurk et al., 1989; Eding et al., 1999), it is likely that these intersex fish were genetically male. Prolonged periods of treatment and higher doses of MT would probably complete feminization of the testis, resulting in a normal and functional ovary ( $\mathrm{XY}$ females). The feminizing effect of androgens was first reported in Channel catfish (Goudie et al., 1983), in which 99\% of larvae fed 6 mg $17 \alpha$-ethynyltestosterone $\mathrm{kg}^{-1}$ for 21 days after yolk-sac absorption developed into females. These sex reversed females were stable for at least 2.5 years and showed normal ovary development.

The ontogenesis of the seminal vesicle begins as simple protrusions from the vas efferent, becoming more complex with age. During this process, the base of the seminal vesicle forms up to 50 finger-like extensions, each $3-4 \mathrm{~cm}$ long and anchored on each side of the sperm ducts. In adult fish, the basal portion is flattened and wide, and contains the finger-like extensions (Fishelson et al., 1994). MT treatments inhibited the development of the seminal vesicle finger-like extensions in all males treated with MT at $20 \mathrm{mg}$ $\mathrm{kg}^{-1}$ for days $12-40$ and days 12-47 after hatching and at 50 $\mathrm{mg} \mathrm{kg}^{-1}$ for days $12-33$ and days $12-40$ after hatching. The inhibition of seminal vesicle development was stable for at least 14 months and did not affect testis development or G$\mathrm{SI}$, despite some cases of unilateral intersex or unilateral sterile gonads.

The primary function of the seminal vesicle is the production of a fluid containing various active compounds including steroid glucuronides. The glucuronides act as sex pheromones, which promote ovarian growth and development in pubertal females (van Weerd, 1990), and activate female responsiveness and induce ovulation, thereby improving fertilization in adults (Resink, 1988). However, males with incomplete seminal vesicle development were able to sexually stimulate females maintained in the same tank, as were the control males. At
10 months after hatching, females fed the MT diet at $20 \mathrm{mg}$ $\mathrm{kg}^{-1}$ for days 12-47 after hatching had a G-SI of $8.3 \%$, which was not significantly different from that in control females (9.4\%). In the same group, MT-treated males had the lowest SV-SI (0.08\%; data for only five males) compared with control males $(0.29 \%)$. If males with incomplete seminal vesicle development were not able to stimulate normal ovarian development, a decrease in female G-SI would be expected with an increasing duration of MT treatment. This effect was observed in fish treated with MT for days 12-33 and days 12-40 after hatching, but not in fish treated with MT for days 12-47 after hatching. Therefore, it appears that G-SI variance in females was due to MT treatment rather than to the lack of male stimuli. It seems that MT affected the development of seminal vesicles, but it did not affect their function. However, as all fish received a water supply from the same recirculating system, it is possible that pheromones produced by control males were diluted in the water system and may have stimulated females in other tanks.

MT treatments at both 20 and $50 \mathrm{mg} \mathrm{kg}^{-1}$ also delayed urogenital papilla differentiation. At 4 months after hatching, control fish could be sexed by papilla morphology (pointed and elongated in males and round with a longitudinal cleft in females), whereas in general, MT-treated males and females had a papilla with similar morphology. After sexual maturation (10 months after hatching), all MT-treated fish showed a differentiated male and female papilla, corresponding to a male and female gonad. However, males from treatment groups that received prolonged treatment with MT had a shorter papilla compared with control males. Similarly, in catfish fed

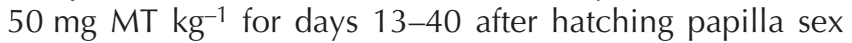
was not correlated with gonad sex at a young age. At day 40 after hatching, $100 \%$ of these fish had a male-like papilla, whereas $90 \%$ of these fish had female gonads, as revealed at dissection (Eding et al., 1999). 
Table 6. Intratesticular semen quality of 14-month-old African catfish, Clarias gariepinus, treated with two cPS injections at 8 and 10 mg $\mathrm{kg}^{-1}$ given with a $48 \mathrm{~h}$ interval and sampled $12 \mathrm{~h}$ after the second injection (stripping experiment)

\begin{tabular}{|c|c|c|c|c|c|c|}
\hline & \multicolumn{3}{|c|}{ MT-treated* } & \multicolumn{3}{|c|}{ MT-control $^{+}$} \\
\hline & \multicolumn{2}{|c|}{ cPS-treated } & \multirow{2}{*}{$\begin{array}{l}\text { cPS-control } \\
\text { Non-stripped }\end{array}$} & \multicolumn{2}{|c|}{ cPS-treated } & \multirow{2}{*}{$\begin{array}{l}\text { CPS-control } \\
\text { Non-stripped }\end{array}$} \\
\hline & Stripped & Non-stripped & & Stripped & Non-stripped & \\
\hline Fish $(n)$ & 10 & 9 & 22 & 4 & 11 & 15 \\
\hline G-SI (\%) & $1.92 \pm 0.78^{\mathrm{a}}$ & $2.11 \pm 1.31^{\mathrm{a}}$ & $1.15 \pm 0.22^{b}$ & $1.10 \pm 0.36^{\mathrm{ab}}$ & $1.63 \pm 0.48^{\mathrm{a}}$ & $1.01 \pm 0.22^{b}$ \\
\hline SV-SI (\%) & $0.14 \pm 0.04^{\mathrm{a}}$ & $0.10 \pm 0.03^{a b}$ & $0.08 \pm 0.03^{b}$ & $0.58 \pm 0.19^{a}$ & $0.62 \pm 0.20^{\mathrm{a}}$ & $0.49 \pm 0.27^{a}$ \\
\hline Volume (ml) & $27.7 \pm 16.3^{a}$ & $29.6 \pm 28.6^{a}$ & $10.3 \pm 5.3^{b}$ & $16.1 \pm 10.5^{\mathrm{a}}$ & $17.9 \pm 9.8^{\mathrm{a}}$ & $11.0 \pm 5.5^{b}$ \\
\hline Spermatocrit (\%) & $10.7 \pm 3.8^{\mathrm{b}}$ & $8.3 \pm 3.5^{b}$ & $13.3 \pm 7.3^{\mathrm{a}}$ & $12.5 \pm 5.9^{\mathrm{b}}$ & $12.9 \pm 4.8^{b}$ & $23.9 \pm 11.1^{\mathrm{a}}$ \\
\hline Cells ml-1 $\left(\times 10^{9}\right)$ & $4.7 \pm 2.2^{b}$ & $3.9 \pm 1.9^{b}$ & $7.2 \pm 1.8^{\mathrm{a}}$ & $4.9 \pm 2.3^{b}$ & $6.8 \pm 2.7^{b}$ & $9.2 \pm 4.3^{\mathrm{a}}$ \\
\hline Absorbance at $505 \mathrm{~nm}$ & $0.064 \pm 0.036^{a}$ & $0.057 \pm 0.038^{\mathrm{a}}$ & $0.068 \pm 0.043^{a}$ & $0.052 \pm 0.043^{b}$ & $0.119 \pm 0.057^{a}$ & $0.126 \pm 0.074^{a}$ \\
\hline Cells per fish $\left(\times 10^{9}\right)$ & $107.1 \pm 38.8^{\mathrm{a}}$ & $86.1 \pm 55.7^{a b}$ & $69.3 \pm 29.2^{b}$ & $69.2 \pm 39.2^{\mathrm{a}}$ & $107.5 \pm 45.2^{\mathrm{a}}$ & $102.0 \pm 68.8^{a}$ \\
\hline
\end{tabular}

CPS: carp pituitary suspensions; G-SI: gonadosomatic index; MT: $17 \alpha$-methyltestosterone; SV-SI: seminal vesicle-somatic index.

${ }^{*}$ Males with incomplete seminal vesicles as a result of $17 \alpha$-methyltestosterone treatment during larval stages.

${ }^{+}$Males with normal seminal vesicles that were fed control diet during larval stages.

abMeans within the same MT group (treated or control) and in the same row with the same superscript are not significantly different, according to Duncan's multiple-range test $(P<0.05)$.

In contrast to other observations in MT-treated fish (Eding et al., 1999), stripping of semen was possible only after cPS treatment, and the absence of the seminal vesicle finger-like extensions appeared to facilitate this process. Ten of nineteen cPS-treated males with incomplete seminal vesicle (MT-treated) could be stripped, compared with only 4 of 15 cPS-treated males with normal seminal vesicle. The sperm concentration in the stripped fluid from MT-treated fish was slightly higher and these spermatozoa were generally more active (motility) compared with those in the stripped fluid from MT-control fish. However, sperm auto-activation was always present. It is possible that, during stripping, semen was contaminated with urine, which activates spermatozoa, as it normally occurs during semen collection in European catfish (Linhart and Billard, 1994). Hatching rates produced with the stripped fluid $(58.9 \%)$ were not different from those produced with intratesticular semen from the same MT-treated males (56.5\%). The mean sperm:egg ratio for stripped fluid was $21.0 \times 10^{4}$ and for intratesticular semen the ratio was $2.1 \times 10^{4}$ spermatozoa per egg. Because the effective insemination ratio for fresh semen in this species is $1.5 \times 10^{4}$ sperm cells per egg (Rurangwa et al., 1998), it is possible that in the present study the quality of spermatozoa in the stripped fluid was overestimated. High hatching rates were also produced with stripped fluid in the same fish species, after treatment with Clarias pituitary suspension (van Der Waal, 1985), but these males were captured in the wild during their natural breeding season.

Spermiogenesis, according to the parameters analysed in the present study, was not affected by MT treatment, compared with the MT-control group. CPS treatment increased G-SI and intratesticular semen volume and decreased spermatocrit and sperm concentration in all CPStreated fish compared with cPS-control fish. However, sperm production per fish was not increased. Testicular hydration with increased semen volume and decreased spermatocrit after pituitary suspension treatments has been described for the African catfish (Hecht et al., 1982), the European catfish (Linhart and Billard, 1994) and the South American catfish, Rhamdia sapo (Espinach Ros et al., 1984).

The minimum effective MT dose and the optimum period of treatment used to inhibit seminal vesicle development in male African catfish was $20 \mathrm{mg} \mathrm{kg}^{-1}$ for days $12-40$ after hatching. Males developed normal testes with occasional oocytes that tended to disappear before sexual maturation. Applying pressure directly on the testes is difficult in this species as the testes are located deep in the posterior end of the body cavity and are covered by abdominal organs. The absence of the seminal vesicle finger-like extensions induced by treatment with MT facilitated stripping compared with normal fish, as observed by Eding et al. (1999). However, in the present study, stripping was possible only when the fish were treated with a maturational hormone, in this case, cPS. MT treatments did not affect the quality or quantity of semen.

The authors express their gratitude to B. Vargas for statistical support and to Y. Fessehaye, M. Yagoub, E-J. Lock and M. ter Veld for technical assistance during sampling. This study is part of A. T. M. Viveiros's PhD project and was supported by Fundação Coordenação de Aperfeiçoamento de Pessoal de Nível Superior (CAPES), Brazil.

\section{References}

Baroiller JF, Guiguen Y and Fostier A (1999) Endocrine and environmental aspects of sex differentiation in fish Cellular and Molecular Life Sciences 55 910-931

Christianus A, Siraj SS, Harmin SA and Nordin WMW (1998) Morphology and histology of the gonad of matured male river catfish, Mystus 
nemurus (Cuvier \& Valenciennes) Malaysian Applied Biology 27 103-106

Ciereszko A and Dabrowsky K (1993) Estimation of sperm concentration of rainbow trout, whitefish and yellow perch using a spectrophotometric technique Aquaculture 109 367-373

Davis KB, Simco BA, Goudie CA, Parker NC, Cauldwell W and Snellgrove R (1990) Hormonal sex manipulation and evidence for female homogamety in channel catfish General and Comparative Endocrinology 78 218-223

Davis KB, Goudie CA, Simco BA, Tiersch TR and Carmichael GJ (1992) Influence of dihydrotestosterone on sex determination in channel catfish and blue catfish: period of developmental sensitivity General and Comparative Endocrinology 86 147-151

Dunham RA (1993) Observations on controlled artificial spawning of Channel catfish Progressive Fish Culturist 55 60-61

Eding EH, Bouwmans A and Komen J (1999) Effects of methyltestosterone and 11-keto-androstenedione on sex differentiation in African catfish, Clarias gariepinus. Conference Proceedings of the Reproductive Physiology of Fish, Bergen, Norway

Espinach Ros A, Amutio VG, Mestre Arceredillo JP, Orti G and Nani A (1984) Induced breeding of the South American catfish, Rhamdia sapo (Cuvier \& Valenciennes) Aquaculture 37 141-146

Fishelson L, van Vuren JHJ and Tyran A (1994) Ontogenesis and ultrastructure of seminal vesicles of the catfish, Clarias gariepinus. Journal of Morphology 219 59-71

Goudie CA, Redner BD, Simco BA and Davis KB (1983) Feminization of Channel catfish by oral administration of steroid sex hormones Transactions American Fishery Society 112 670-672

Guerrero RD (1975) Use of androgens for the production of all-male Tilapia aurea (Steindachner) Transactions American Fishery Society 2 342-348

Hecht T, Saayman JE and Polling L (1982) Further observations on the induced spawning of the sharptooth catfish, Clarias gariepinus (Clariidae: Pisces) Water SA 8 101-107

Hogendoorn H (1979) Controlled propagation of the African catfish, Clarias lazera (Cuvier \& Valanciennes). I. Reproductive biology and field experiments Aquaculture 17 323-333

Legendre M (1986) Seasonal changes in sexual maturity and fecundity, and hCG-induced breeding of the catfish, Heterobranchus longifilis val. (Clariidae) reared in Ebrie lagoon (Ivory Coast) Aquaculture 55 201-213

Linhart $\mathbf{O}$ and Billard R (1994) Spermiation and sperm quality of European catfish (Silurus glanis L.) after implantation of GnRH analogues and injection of carp pituitary extract Journal of Applied Ichthyology $\mathbf{1 0}$ 182-188

Liu S and Yao Z (1995) Self-fertilization of hermaphrodites of the teleost Clarias lazera after oral administration of $17 \alpha$-methyltestosterone and their offspring Journal of Experimental Zoology 273 527-532
Oteme ZJ, Nunez Rodriguez J, Kouassi CK, Hem S and Agnese JF (1996) Testicular structure, spermatogenesis and sperm cryopreservation in the African clariid catfish Heterobranchus longifilis (Valenciennes, 1840) Aquaculture Research 27 805-813

Patiño R, Davis KB, Schoore JE, Uguz C, Strüssmann CA, Parker NC, Simco BA and Goudie CA (1996) Sex differentiation of channel catfish gonads: normal development and effects of temperature Journal of Experimental Zoology 276 209-218

Resink JW (1988) Steroid Glucuronides as Pheromones in the Reproduction of the African Catfish, Clarias gariepinus PhD Thesis, University of Utrecht, Utrecht, The Netherlands

Richter CJJ (1976) The African catfish, Clarias lazera, a new possibility for fish culture in tropical regions? In Aspects of Fish Culture and Fish Breeding pp 51-74 Ed. EA Huisman, Miscellaneous papers 13 Lanbouwhogeschole Wageningen, Wageningen

Rurangwa E, Roelants I, Huyskens G, Ebrahimi M, Kime DE and Ollevier F (1998) The minimum effective spermatozoa:egg ratio for artificial insemination and the effects of mercury on sperm motility and fertilization ability in Clarias gariepinus. Journal of Fish Biology $\mathbf{5 3}$ 402-413

Short RV (1982) Sex determination and differentiation. In Reproduction in Mammals: 2. Embryonic and Fetal Development pp 70-113 Eds CR Austin and RV Short. Cambridge University Press, Cambridge, UK

Tan Fermin JD, Miura T, Adachi S and Yamauchi K (1999) Seminal plasma composition, sperm motility and milt dilution in the Asian catfish, Clarias macrocephalus (Gunther) Aquaculture 171 323-338

van den Hurk R, Richter CJJ and Janssen Dommerholt J (1989) Effects of $17 \alpha$-methyltestosterone and 11-beta-hydroxyandrostenedione on gonad differentiation in the African catfish, Clarias gariepinus. Aquaculture 83 179-192

van der Waal BCW (1985) Stripping male Clarias gariepinus of semen Aquaculture 48 137-142

van Oordt PGWJ, Peute J, van den Hurk R and Viveen WJAR (1987) Annual correlative changes in gonads and pituitary gonadotropes of feral African catfish, Clarias gariepinus. Aquaculture 63 27-41

van Weerd JH (1990) Pheromones and Ovarian Growth in the African Catfish Clarias gariepinus PhD Thesis, Wageningen Agricultural University, Wageningen, The Netherlands

Received 11 April 2001

First decision 15 June 2001.

Accepted 5 July 2001. 